\title{
Forming C/Cu Composite on Surface of Structural Chrome-Nickel Steel by Ion Beam Deposition
}

\author{
Igor V. Rodionov \\ Department of Welding and Metallurgy \\ Yuri Gagarin State Technical University \\ Saratov, Russia \\ iv.rodionov@mail.ru
}

\author{
Lyubov E. Kuts \\ Department of Welding and Metallurgy \\ Yuri Gagarin State Technical University \\ Saratov, Russia \\ iv.rodionov@mail.ru
}

\author{
Irina V. Perinskaya \\ Department of Welding and Metallurgy \\ Yuri Gagarin State Technical University \\ Saratov, Russia \\ iv.rodionov@mail.ru
}

\begin{abstract}
We studied an impact of the technological processes, used for forming $\mathrm{C} / \mathrm{Cu}$ composite coated surface of medical implants, on the mechanical characteristics and biocompatibility of resulting coatings. These implants, designed for temporary functioning, were made from X12CrNiTi18-9 stainless steel by ion-beam modification (IBM) of copper ions in a carbon dioxide environment. The optimal technological parameters of modifying steel samples were determined: an acceleration voltage is $U_{\|}=100-150 \mathrm{kV}$ and a radiation dose is $F$ $=(1-4) \cdot 10^{17}$ ion $/ \mathrm{cm}^{2}$. The data on secondary ionic mass spectrometry (SIMS) and laser emission microspectral analysis indicated that the presence of $2-5 \% \mathrm{Cu}$ content in the $\mathrm{C} / \mathrm{Cu}$ coating composite on the surface of medical products (e.g. osteofixation devices), made from chromium-nickel steel, provided them with required bacteriostatic quality.
\end{abstract}

Keywords - ion-beam modification, structural chromiumnickel steel, composite coating, microhardness of the surface, bacteriostatic properties.

\section{INTRODUCTION}

In mechanical engineering and instrumentation, high alloy steels are widely used to create various engineering metal structures. In order to impart strength, anticorrosive properties and electrical insulation to their surfaces, various techniques of surface modification and application of functional coatings are developed. These techniques include mechanical, thermal and chemical treatments, as well as modern laser, electronbeam, ultrasonic, and ion-plasma technologies.

Stainless chromium-nickel steels (for example, X12CrNiTi18-9 or X12CrNiTi18-10) are considered perspective construction materials. They find highly effective application in shipbuilding, aircraft construction, vacuum technology, chemical instrumentation, centrifuging and other industrial fields. Currently, chromium-nickel steels are widely used in development of new generation medical implantable structures, designed for reconstructive implantation surgery of the musculoskeletal system. However, it is necessary to improve the existing (and to develop fundamentally new) technological processes of surface treatment, aimed at refining functional properties, reliability and durability of biomedical implants and devices. It is worth noting that finishing methods, used for forming the specific physicochemical state of the product surface, play a decisive role on most occasions.

The implantable structures belong to the most demanded products among medical equipment for orthopedic treatment. They operate in a wide range of alternating cyclic, dynamic and static loads, which appear in the course of their inserting and functioning. They are also exposed to corrosive liquid biomedia and pathogenic bacterial flora. Engraftment reliability of such structures is achieved by applying various technological processes, such as micro-arc oxidation, nitriding, electro-plasma sputtering, methods of gas thermal oxidation, treatment with high frequency currents, etc. [1-15]. However, none of these methods can guarantee obtaining desirable surfaces with certain composition, properties and structure. The most promising technology for obtaining specific mechanical, physicochemical and biocompatible properties of the metal surface layer on the implants and biomedical devices is an ion-beam modification (IBM) [16$18]$.

Being one of highly controlled and accurate methods for modifying different construction materials, IBM leads to significant changes in the physicochemical state of the surface layer and, consequently, its functional characteristics, such as endurance, durability, wear resistance, corrosion resistance and biological compatibility [16]. At the same time, lack of ionbeam treatment regimens for many orthopedic implant materials and temporarily functioning biomedical devices (in particular, implants manufactured from chromium-nickel steels), as well as an absence of scientific data related to the effect of IBM on mechanical properties, structural parameters, along with chemical and phase compositions of X12CrNiTi18-9 and X12CrNiTi18-10 biotolerant steels, indicates an importance of conducting experimental studies in this field.

Another important issue of applying ion-beam processing to modification of steel implant products is giving medicated properties (e.g. the ability to inhibit bacterial growth) to their 
surfaces. At present, oxide and hydroxyapatite coatings with antimicrobial $\left(\mathrm{Ag}^{+}\right)$and antiplatelet $\left(\mathrm{La}^{+}\right)$properties are used to reduce the risk of postoperative complications due to inflammatory processes associated with metal implants in the bone tissue. In case of temporary implants, designed for limited time use in orthopedic treatment, the presence of components with bacteriostatic effects (composite coatings and medical preparations) on the surface of their direct contact with surrounding tissues is more significant.

The bacteriostatic effect is caused by a complex of therapeutic properties inherent to copper-containing coatings and medical formulations against pathogenic microflora. Such coatings inhibit reproduction of the bacteria and other microorganisms, thus causing bacteriostasis.

The scientific goal of our study was an experimental investigation of the technological process, causing the formation of $\mathrm{C} / \mathrm{Cu}$ biocompatible composite with a bacteriostatic effect, on the surface of stainless chromiumnickel steels via using the method of ion-beam modification, characterized by high reproducibility and controllability.

\section{METHODS OF EXPERIMENTAL STUDIES}

The prototypes were made of stainless biotolerant X12CrNiTi18-9 steel, widely used in manufacturing orthopedic wires and rod clamps for external osteosynthesis devices. Superficially, they resembled plates with dimensions $25 \times 20$ $\times 2 \mathrm{~mm}$ and were cut from a metal sheet by electrical discharge machining method.

Samples were processed by sandblasting with free abrasive $\mathrm{Al}_{2} \mathrm{O}_{3}$ under positive pressure of air abrasive jet at $0.65 \mathrm{MPa}$ for two minutes. Such preliminary procedure contributed to the creation of original surface microroughness for obtaining structurally heterogeneous film coatings, designed to enhance physical and mechanical connection of implants with a bone tissue.

To increase an efficiency of the subsequent ion-beam modification, as well as to reduce the probability of pathogenic bacteria development, sample surfaces were preliminarily treated by ultrasonic cleaning in an alcohol solution at a frequency of ultrasound oscillations of $22 \mathrm{kHz}$ for 3 min, using a Kristall-1.5 apparatus. This procedure helped cleaning the surface from existing fat and mechanical contaminants of different chemical nature. Such contaminants could provide a nutritious environment for pathogenic microflora.

Ion-beam modification of the prototype surface was carried out in a controlled environment of carbon dioxide $\left(\mathrm{CO}_{2}\right)$ by the introduction of copper ions $\left(\mathrm{Cu}^{+}\right)$, using the Vesuvium-5 ion implanter unit with acceleration voltage $\mathrm{U}_{\|}=$ $100-150 \mathrm{kV}$ within the radiation dose range $\mathrm{F}=(1-4) \cdot 10^{17}$ ion $/ \mathrm{cm}^{2}$. Under such treatment, in the conditions of energy impact by copper ions, a $\mathrm{C} / \mathrm{Cu}$ composite coating with increased mechanical strength and bacteriostatic properties was formed on the surface of X12CrNiTi18-9 steel (Fig. 1).
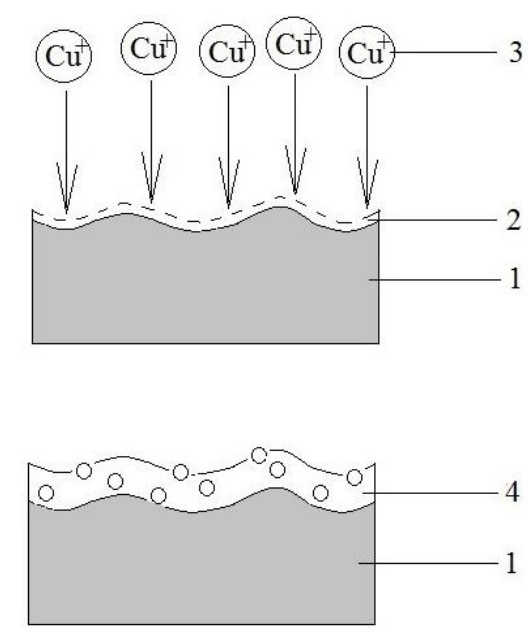

Fig. 1. The process of forming the $\mathrm{C} / \mathrm{Cu}$ composite structure on the surface of X12CrNiTi18-9 steel by ion-beam modification: 1 -steel base; 2 -carbon-containing layer; 3 - copper ions; $4-\mathrm{C} / \mathrm{Cu}$ composite coating

Elemental composition of the modified surface was determined by the method of secondary ion mass spectrometry (SIMS), based on TOF.SIMS5 mass spectrometer. The presence of copper, embedded in the chemical composition of the carbon-containing coating, was determined, using a laser emission micro spectrum analyzer Spectrum-2000. The source of spectra excitation was a Nb-based laser $(\lambda=1.06 \mu \mathrm{m})$, operating in a giant pulse mode with a duration of $10 \mathrm{~ns}$. The pulse repetition rate was $25 \mathrm{~Hz}$, the pulse energy was $120 \mathrm{~mJ}$, and the power density was $10^{10}-10^{12} \mathrm{~W} / \mathrm{cm}^{2}$. The spectrograph, DFS-458C, was used as a dispersing device. The diameter of the laser crater at a single pulse averaged $200 \mu \mathrm{m}$, while the crater depth was $150 \mu \mathrm{m}$. The chemical composition of the studied surface was determined at several sections from the obtained spectra of chemical elements.

The morphology of the coatings was investigated by scanning electron microscopy (SEM) at various magnifications, using analytical equipment, such as MIRA II LMU, Tescan. Spectroscopic infrared analysis was performed on a single-beam Nikolet-6700 instrument.

Microhardness measurements were completed in accordance with the Federal Standard 6450-76 on the PMT-3 device by means of indenting a diamond indenter at a load of $0.39 \mathrm{~N}$, applied for $15 \mathrm{~s}$. At the same time, an accuracy of the imprint measurement was $\pm 0.3 \mu \mathrm{m}$, and the confidence interval was $\pm 3-4 \mathrm{GPa}$.

The fatigue strength tests were conducted, using the alternating cantilever bending method at a frequency of 22.5 $\mathrm{Hz}$.

For conducting laboratory tests on experimental animals (rabbits of the Black Giant breed), the surfaces of the prototypes of steel implants (standard screw rods and smooth orthopedic wires for transosseous osteosynthesis) were modified, according to the original method of ion-beam processing (Fig. 2). 

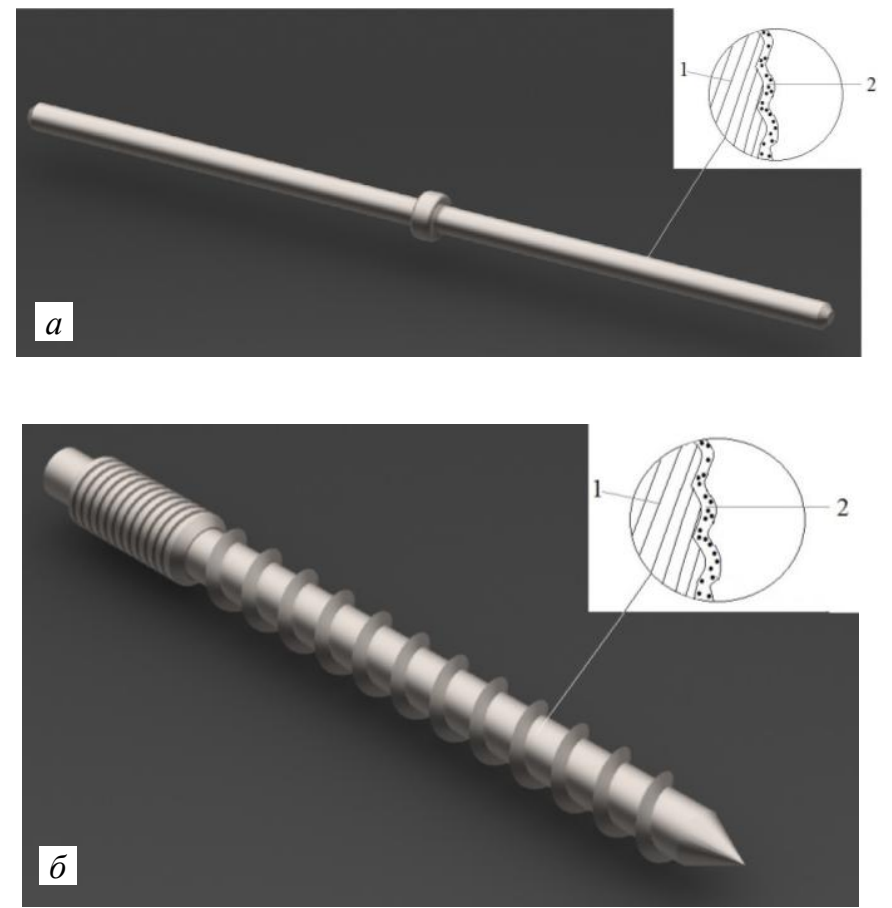

Fig. 2. An orthopedic wire $(a)$ and a screw rod $(b)$ from chromium-nickel steel with $\mathrm{C} / \mathrm{Cu}$ composite coating, formed by ion-beam modification: 1 steel base; 2 - C/Cu composite structure

The resulting rod and orthopedic wire structures were implanted into the tibia of animals for 45 days. Then they were removed from the body and examined by optical microscopy in order to determine an effectiveness of the intergrowth of their surfaces with bone tissues.

\section{STUdy RESUlts AND THEIR ANALYSIS}

In the course of our experimental studies, we identified the optimal technological regimens for the formation of $\mathrm{C} / \mathrm{Cu}$ composite coatings on the surface of steel substrates. The coatings were generated by means of ion-beam modification in a controlled environment of carbon dioxide with an introduction of copper ions $\left(\mathrm{Cu}^{+}\right)$. The regimens with acceleration voltage $U_{\|}=100-150 \mathrm{kV}$ and the radiation dose range of $F=(1-4) \cdot 10^{17} \mathrm{ion} / \mathrm{cm}^{2}$ provided the synthesis of carbon, carbon-containing fragments and copper ions, forming thin $\mathrm{C} / \mathrm{Cu}$-based coating on the surface of the prototypes.

To implement the ion-beam process inside the receiving chamber of the ion implanter unit, we created a vacuum of $10^{-4} \mathrm{~Pa}$. A carbon-containing gas $\left(\mathrm{CO}_{2}\right)$ was dosed under the automatic control. The optimum vacuum pressure range for the formation of the $\mathrm{C} / \mathrm{Cu}$ composite structure was identified at the level of $5 \cdot 10^{-2}-5 \cdot 10^{-3}$. Outside the boundaries of this range, undesirable processes occurred, such as soot formation and decrease in the rate of carbon-dioxide adsorption on the surface of steel samples. It was established that an acceleration voltage below $100 \mathrm{kV}$ and above $150 \mathrm{kV}$, as well as the radiation dose outside the range of $(1-4) \cdot 10^{17} \mathrm{ion} / \mathrm{cm}^{2}$, did not provide the formation of a $\mathrm{C} / \mathrm{Cu}$ composite coating with required bacteriostatic properties. The study of X12CrNiTi18-9 steel surface composition by SIMS method showed the presence of copper and carbon-containing compounds, such as $\mathrm{CH}, \mathrm{CH}_{2}, \mathrm{CH}_{4}, \mathrm{CO}, \mathrm{CO}_{2}$ (Table 1).

TABLE I. ELEMENTAL COMPOSITION BASED ON SIMS RESULTS

\begin{tabular}{|c|c|c|c|}
\hline \multirow{2}{*}{$\begin{array}{c}\text { Element, } \\
\text { compound }\end{array}$} & \multirow{2}{*}{$\begin{array}{c}\text { Atomic } \\
\text { mass }\end{array}$} & \multicolumn{2}{|c|}{ Content, relative units } \\
\cline { 3 - 4 } & & $\begin{array}{c}\text { Non-modified } \\
\text { prototype }\end{array}$ & Modified prototype \\
\hline $\mathrm{C}$ & 12 & 500 & 600 \\
\hline $\mathrm{CH}$ & 13 & - & $5 \cdot 10^{4}$ \\
\hline $\mathrm{CH}_{2}$ & 14 & - & 230 \\
\hline $\mathrm{CH}_{3}$ & 15 & - & 300 \\
\hline $\mathrm{CH}_{4}$ & 16 & - & 220 \\
\hline $\mathrm{H}_{2} \mathrm{O}$ & 18 & - & 700 \\
\hline $\mathrm{N}_{2},(\mathrm{CO})$ & 28 & - & 4700 \\
\hline $\mathrm{O}_{2}$ & 32 & 18 & 13 \\
\hline $\mathrm{CO}_{2}$ & 44 & - & 750 \\
\hline $\mathrm{Fe}$ & 56 & 60 & 400 \\
\hline $\mathrm{FeO}$ & 72 & 170 & 130 \\
\hline $\mathrm{Cu}$ & 63.5 & - & 1200 \\
\hline
\end{tabular}

Under an impact of copper ion energy on carboncontaining fragments, adsorbed on the surface, the $\mathrm{C} / \mathrm{Cu}$ coating was synthesized, repeating the shape of the steel-base surface without reduction in its total open porosity and osseointegration capacity. The formed coating had a submicrometric polycrystalline structure with the presence of complexly oriented microparticles of different geometric shapes (Fig. 3).
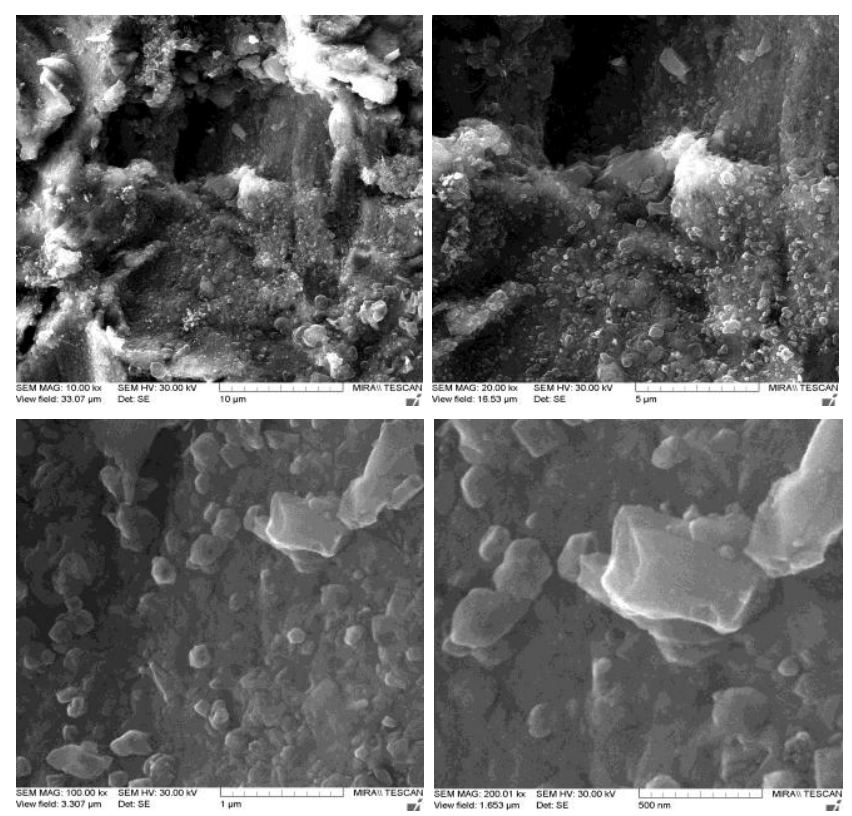

Fig. 3. A composite C/Cu-based coating, formed on the surface of steel samples in a vacuum environment of carbon dioxide

During the implantation of copper ions, the structure of the surface and near-surface layers of chromium-nickel steel went through a grain size reduction until the emergence of amorphous phase, followed by the nucleation of 
polycrystalline disordered inclusions and an increase in their concentration.

Infrared spectroscopic study of the modified surface of steel prototypes showed that nanostructured carbon was synthesized after the IBM. Its presence was confirmed by spectral peaks in the region of 2780-2925 $\mathrm{cm}^{-1}$, which corresponded to the stretching vibrations of $\mathrm{CH}$ groups (Fig. $4)$.

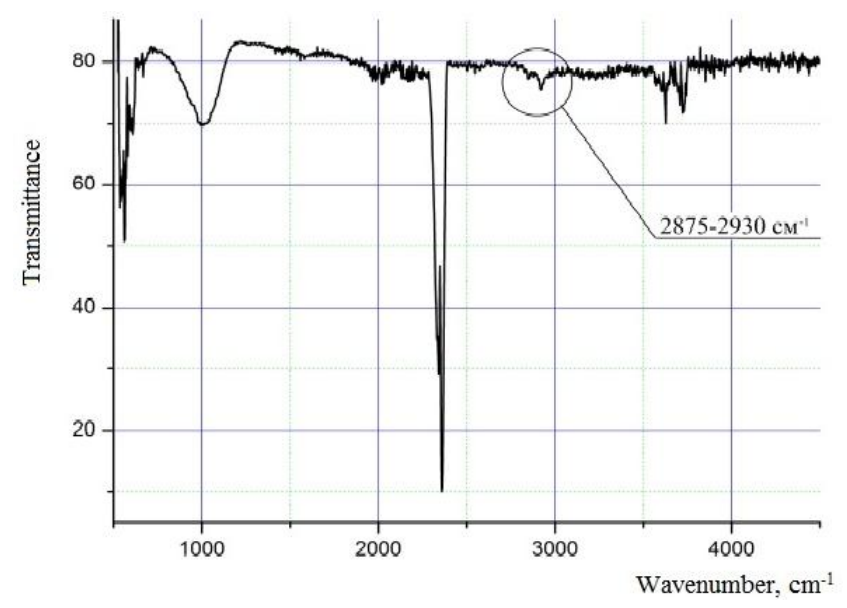

$a$

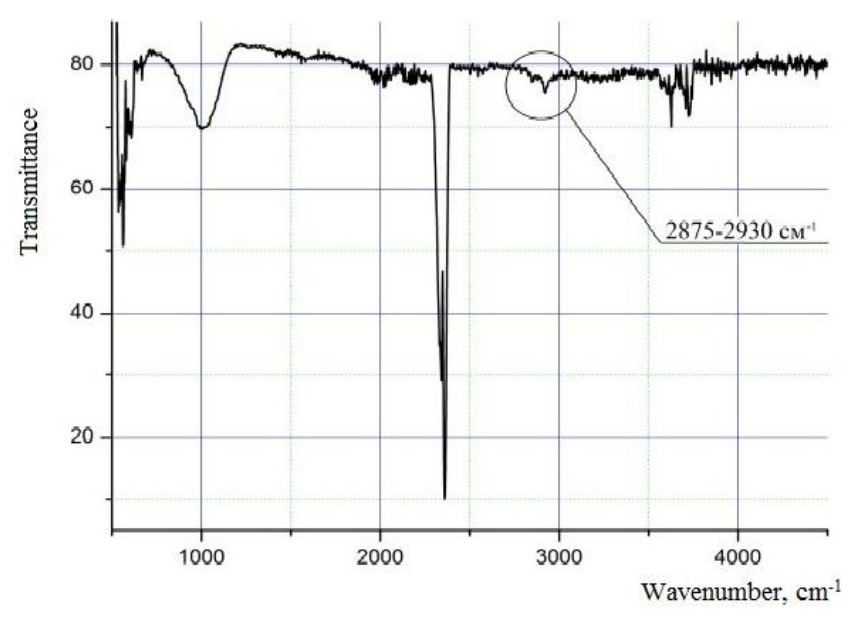

$b$

Fig. 4. The results of infrared spectroscopy of steel prototype surface: $a$ - before IBM; $b$ - after IBM

The presence of microquantities of copper ions with high bacteriostatic properties in the $\mathrm{C} / \mathrm{Cu}$ composite coating was confirmed by a laser microspectral analysis (Fig. 5).

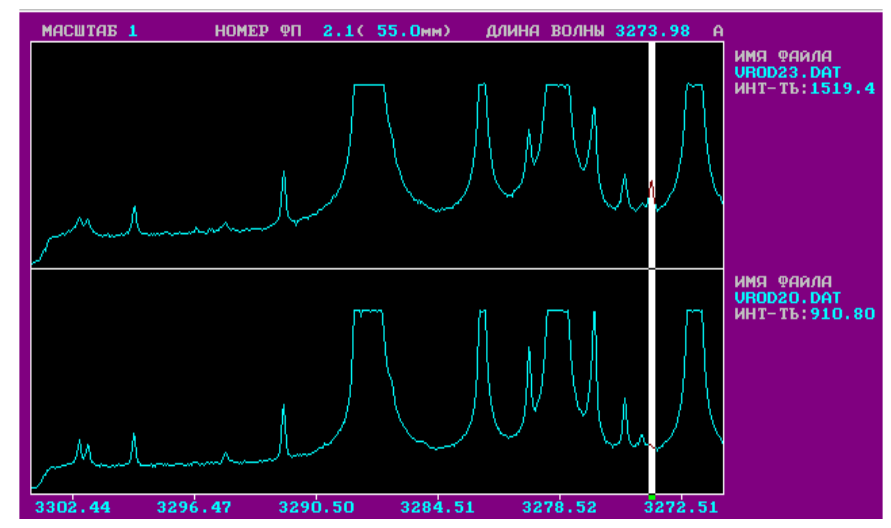

Fig. 5. Laser spectrograms of $\mathrm{Cu}$ with $\lambda=327.39 \mathrm{~nm}$ (marked by a white line) of two different sections of an ion-modified surface of X12CrNiTi18-9 steel (the remaining spectra belong to the elements that make up the alloy)

When $\mathrm{C} / \mathrm{Cu}$ coatings were formed, copper ions were distributed along and inside their surfaces. The doses of copper ions, necessary to impart a bacteriostatic effect to the resulting coatings, were $1 \cdot 10^{17}-4 \cdot 10^{17} \mathrm{ion} / \mathrm{cm}^{2}$, which was essentially the concentration of copper ions that caused this medical effect.

This fact was confirmed by the properties of copper cations, introduced by the ion implantation method with the precision of one $\mathrm{Cu}^{+}$ion, based on measuring the charges of implanted ions. An absence of ions with a charge of two, three, or more in a modern ion implantation unit was guaranteed by the designs of an ion source and a mass separator.

Using secondary ion mass spectrometry and laser microspectral analysis, we discovered that the copper content in the synthesized $\mathrm{C} / \mathrm{Cu}$ composite did not exceed 5\%, which allowed achieving the required efficiency of bacteriostatic action of copper in the coating on implantable orthopedic structures of the rod wire and rod clamp types.

We have experimentally established that the implantation of $\mathrm{Cu}^{+}$ions in the $\mathrm{CO}_{2}$ medium led to a significant increase in the microhardness of the medical steel surface. From our measurements, we discovered that the value of microhardness was essentially dependent on the dose of implanted copper ions. The dose had a maximum value of $34 \mathrm{GPa}$ at $\mathrm{F}=2.8$. $10^{17} \mathrm{ion} / \mathrm{cm}^{2}$ and $U_{\|}=150 \mathrm{kV}$, and the minimum value of 24 $\mathrm{GPa}$ at $\mathrm{F}=1,1 \cdot 10^{1 /} \mathrm{ion} / \mathrm{cm}^{2}$ and $\mathrm{U}_{\|}=100 \mathrm{kV}$ (Table 2).

Compared with unmodified surface microhardness of steel samples, copper-modified surface microhardness increased by over 1.5 times, which was due to the formation of a highdensity thin-film carbon-containing system.

The greatest increase in fatigue strength occurred at the same dose of $\mathrm{Cu}^{+}$ion implantation, at which the maximum microhardness values of the treated surface were obtained. This increase was virtually independent of acceleration voltage of copper ions in investigated range (Table 2). 
TABLE II. DEPENDENCE OF MICROHARDNESS VALUES AND FATIGUE STRENGTH OF STEEL PROTOTYPE SURFACE ON ACCELERATION VOLTAGE AND THE DOSE OF IMPLANTED COPPER IONS

\begin{tabular}{|c|c|c|c|c|}
\hline № & $\begin{array}{c}\text { Acceleration } \\
\text { voltage of } \\
\text { copper cations } \\
\left(\mathbf{C u}^{+}\right), \mathbf{k V} \\
\end{array}$ & $\begin{array}{c}\text { Radiation dose } \\
\text { of copper } \\
\text { cations }\left(\mathrm{Cu}^{+}\right), \\
\text {ion } / \mathbf{c m}^{2} \\
\end{array}$ & $\begin{array}{c}\text { Microhardnes } \\
\text { (H), } \\
\text { GPa }\end{array}$ & $\begin{array}{c}\text { Fatigue } \\
\text { strength } \\
\left(\sigma_{\max }\right), \\
\mathrm{MPa} \\
\end{array}$ \\
\hline 1 & - & - & 23 & 350 \\
\hline 2 & 100 & $1,1 \cdot 10^{17}$ & 24 & 350 \\
\hline 3 & 100 & $1,2 \cdot 10^{17}$ & 31 & 400 \\
\hline 4 & 100 & $2.2 \cdot 10^{17}$ & 33 & 450 \\
\hline 5 & 100 & $2.8 \cdot 10^{17}$ & 33 & 450 \\
\hline 6 & 100 & $3.6 \cdot 10^{17}$ & 31 & 450 \\
\hline 7 & 100 & $4 \cdot 10^{17}$ & 25 & 420 \\
\hline 8 & 150 & $1.1 \cdot 10^{17}$ & 26 & 400 \\
\hline 9 & 150 & $1.2 \cdot 10^{17}$ & 32 & 450 \\
\hline 10 & 150 & $2.2 \cdot 10^{17}$ & 33 & 450 \\
\hline 11 & 150 & $2.8 \cdot 10^{17}$ & 34 & 455 \\
\hline 12 & 150 & $3.6 \cdot 10^{17}$ & 32 & 450 \\
\hline 13 & 150 & $4 \cdot 10^{17}$ & 26 & 440 \\
\hline
\end{tabular}

\section{PRECLINICAL LABORATORY TESTS OF THE PROTOTYPES} FROM X12CRNITI18-9 STEEL WITH ION-MODIFIED SURFACE

We modified the surface of standard orthopedic wires and rod clamp implants from X12CrNiTi18-9 chromium-nickel steel in order to conduct in-vivo studies, using our original technology. Tests for engraftment of the prototypes with and without $\mathrm{C} / \mathrm{Cu}$ coating were carried out in specific stationary clinical conditions on rabbits of the Black Giant breed. The animals were aged 9 months with a living weight of 4.5-5.0 $\mathrm{kg}$. They were divided into two experimental groups of five animals each.

The animals of the first group were equipped with uncoated transosseous steel implants (the control group), while the second group animals had implants with a $\mathrm{C} / \mathrm{Cu}$ coating (the experimental group). In metaphyseal sections of the tibiae, channels were drilled in order to insert implants. The implants were installed manually for a period of 45 days, using the handle from the set of G.A. Ilizarov apparatus. In the postoperative period, all animals underwent preventive antibiotic therapy with cefazolin and the sanitation of the fixator-bone contact zone with a $3 \%$ solution of hydrogen peroxide. Subsequently, clinical and morphological studies were conducted.

Clinical evaluation of the fixator biocompatibility was performed by registering the following characteristics of animal condition, including body temperature, behavior, limb condition, micro mobility of fixators, and the response of animals to clamps. Also, we evaluated the signs of developing inflammatory complications, using a microbiological examination of smears. Finally, the resistance of the rabbits to the extraction of fixators was assessed.

In the course of our experiments, we confirmed that modified fixators fused strongly with adjacent bone tissues without any signs of significant inflammatory phenomena or rejection. The control group did not undergo ion-beam treatment, and the animals developed pronounced rejection reactions, manifested in the form of purulent-inflammatory processes in their tissues. Hence, the fixators in this group had to be removed from the rabbits on the 5th day of the experiment.

We established that the coatings from the $\mathrm{C} / \mathrm{Cu}$ composite on initial micro-rough surfaces of steel samples had the ability of effective physico-mechanical interaction with the bone. In addition, the presence of $\mathrm{Cu}^{+}$ions in the composition of the coating contributed to its antiseptic function by means of preventing long-term inflammatory tissue reactions. This fact was supported by the results of a microbiological analysis of exudate smears. The smears showed an absence of a pathogenic microflora in the area of bone fixator implantation.

Thus, the original technology of ion-beam modification of medical chromium-nickel steel made it possible to manufacture medical transosseous structures (wires and rods) had increased osseointegration capacity, a high level of biocompatibility and bacteriostatic surface effect. All of these findings were confirmed by the results of our preliminary tests of the prototypes, conducted on laboratory animals.

\section{CONCLUSIONS}

In our experiments, we investigated the formation of a $\mathrm{C} / \mathrm{Cu}$ composite coating on the surface of X12CrNiTi18-9 medical steel in a controlled environment of carbon dioxide. This process was implemented by the introduction of $\mathrm{Cu}^{+}$ cations at the Vesuvium-5 ion implanter unit with acceleration voltage $\mathrm{U}_{\|}=100-150 \mathrm{kV}$ in the radiation dose range of $\mathrm{F}=(1$ -4) $\cdot 10^{17}$ ion $/ \mathrm{cm}^{2}$.

We established that implantation of copper cations in a controlled environment of carbon dioxide led to increased microhardness and fatigue strength of the steel prototype surface. Such increase was due to the synthesis of a dense $\mathrm{C} / \mathrm{Cu}$ coating with enhanced mechanical strength in the conditions of copper ion energy impact, occurring in the course of ion-beam modification.

$\mathrm{C} / \mathrm{Cu}$ coatings for conducting experiments in vivo were created by means of original modification process, applied to standard orthopedic wires and transosseous rod implants from X12CrNiTi18-9 steel. The experiments involved the implantation of the orthopedic wires and rod implants in the tibia of laboratory animals for 45 days. The results of preclinical tests on animals showed $100 \%$ engraftment of the fixators in the absence of pronounced immune reactions, purulent-inflammatory processes and tissue rejection. All of these findings indicated high efficiency of original $\mathrm{C} / \mathrm{Cu}$-based composite coatings on medical products made of stainless chromium-nickel steels.

\section{Acknowledgment}

This study was supported by the Russian Federation Ministry of Education and Science within the framework of the Program on Scientific Research at Universities (project No. 11.1943.2017/4.6).

\section{References}

[1] I.V. Rodionov, "Microstructure of biocompatible steam-heat oxide coatings on titanium implants," Metal Science and Heat Treatment, vol. 
55, nos. 11-12, pp. 599-602, 2014.

[2] R. Hazan, R. Brener, U. Oron, "Bone growth to metal implants is regulated by their surface chemical properties," Biomaterials, vol. 14, no. 8, pp. 570-574, 1993.

[3] L.Le Guéhennec, A. Soueidan, P. Layrolle, Y. Amouriq, "Surface treatments of titanium dental implants for rapid osseointegration," Dent. Mater., vol. 23, pp. 844-854, 2007.

[4] K. Kuroda, R. Ichino, M. Okido, and O. Takai, "Effects of ion concentration and $\mathrm{pH}$ on hydroxyapatite deposition from aqueous solution onto titanium by the thermal substrate method," J. Biomed. Mater. Res., vol. 61, no. 3, pp. 354-359, 2002.

[5] S. Fujibayashi, M. Neo, H.M. Kim, T. Kokubo, and T. Nakamura, "Osteoinduction of porous bioactive titanium metal," Biomaterials, vol. 25, no. 3, pp. 443-450, 2004.

[6] Y.T. Sul, C.B. Johansson, S. Petronis et al., "Characteristics of the surface oxides on turned and electrochemically oxidized pure titanium implants up to dielectric breakdown: the oxide thickness, micropore configurations, surface roughness, crystal structure and chemical composition," Biomaterials, vol. 23, no. 2, pp. 491-501, 2002.

[7] J.P. Schreckenbach, G. Marx, F. Schlottig, M. Textor, N.D. Spencer, "Characterization of anodic spark-converted titanium surfaces for biomedical applications," J. Mater. Sci.-Mater. M., vol. 10, no. 8, pp. 453-457, 1999.

[8] B. Yang, M. Uchida, H.M. Kim, X. Zhang, T. Kokubo, "Preparation of bioactive titanium metal via anodic oxidation treatment," Biomaterials, vol. 25, no. 6, pp. 1003-1010, 2004.

[9] Y. Zhao, T. Xiong, and W. Huang, "Effect of heat treatment on bioactivity of anodic titania films," Appl. Surf. Sci., vol. 256, no. 10, pp. 3073-3076, 2010.

[10] B. Feng, J. Weng, B.C. Yang, S.X. Qu, X.D. Zhang, "Characterization of surface oxide films on titanium and adhesion of osteoblast," Biomaterials, vol. 24, no. 25, pp. 4663-4670, 2003.

[11] A. Fomin, M. Fomina, V. Koshuro, I. Rodionov, A. Zakharevich, A Skaptsov, "Structure and mechanical properties of hydroxyapatite coatings produced on titanium using plasma spraying with induction preheating," Ceram. Int., vol. 43, pp. 11189-11196, 2017.

[12] G. Di Girolamo et al., "Microstructure and mechanical properties of plasma sprayed alumina-based coatings," Ceram. Int., vol.. 40, no. 8, pp. 12861-12867, 2014.

[13] I.V. Rodionov, "Application of the air-thermal oxidation technology for producing biocompatible oxide coatings on periosteal osteofixation devices from stainless steel," Inorg. Mater.: Appl. Res., vol. 4, no. 2, pp. 119-126, 2013.

[14] V.A. Koshuro, M.A. Fomina, I.V. Rodionov, A.A. Fomin, "Nanoporous Structure of Coatings Formed by Thermal Spraying of Aluminum Oxide with Further Microarc Oxidation on Titanium Alloy VT6 Implants," Biomed. Eng., vol. 50, no.1, pp. 54-57, 2016.

[15] A. Fomin, S. Dorozhkin, M. Fomina, V. Koshuro, I. Rodionov, A. Zakharevich, N. Petrova, A. Skaptsov, "Composition, structure and mechanical properties of the titanium surface after induction heat treatment followed by modification with hydroxyapatite nanoparticles," Ceram. Int., vol. 42, no. 9, pp. 10838-10846, 2016.

[16] I.V. Rodionov, I.V. Perinskaya, L.E. Kuts, V.V. Perinskii, I.S. Egorov, A.A. Fomin, "Use of Ion Beam Modification and GasThermal Oxidation in the Process of Formation of Structurally Heterogeneous Oxide Coatings for Titanium Medical Implants, ” Biomed. Eng., vol. 51, no. 5, pp. 303-307, 2018.

[17] M. Shafiq et al., "Pulsed ion beam-assisted carburizing of titanium in methane discharge," Chinese Phys. B, vol. 19, no. 1, p. 012801, 2010.

[18] T.R. Rautray et al., "Surface modification of titanium and titanium alloys by ion implantation," Journal of Biomedical Materials Research, Part B: Applied Biomaterials, vol. 93, no. 2, pp. 581-591, 2010. 